\title{
Technological Capabilities of Well Cementing
}

doi:10.2478/mape-2021-0042

Date of submission to the Editor: 03/2021

Date of acceptance by the Editor: 06/2021

MAPE 2021, volume 4, issue 1, pp. 465-478

Tatiana N. Ivanova

ORCID ID: 0000-0003-2284-2949

Tchaikovsky Branch

"Perm National Research Polytechnic Institute",

Federal State Budgetary Institution

of Science "Udmurt Federal Research

Center of the Ural Branch of the Russian Academy

of Sciences", Institute of Mechanics, Russia

Michał Zasadzień

ORCID ID: 0000-0002-3181-9815

Silesian University of Technology, Poland

\section{ANALYSIS OF EXISTING SCHEME OF CEMENTING}

In the current practice, cementing unit TSA-320 (ЦА-320, Russia), cement mixing unit (2SMN-20) and manifold unit (BM-700) are used on the most of fields (Savenok et al., 2020; Moroz et al., 2020; Afanasyev 2012; Baranov et al., 2017).

Cementing truck TSA-320 (Fig. 1) is used for pumping of fluids during well cementing in the process of drilling or workover, as well as for other flushing and squeezing operations on oil and gas wells. To provide the operation under low temperatures, cementing units are equipped with a device for heating of hydraulic part of high-pressure pumps. They are also equipped with a system for monitoring the temperature of the oil in the pump crankcase NTS-320 (НЦ320) with information output to the car dash panel. TSA-320 has a manifold to ensure the simultaneous operation of several units when cementing wells and the adapter for connecting the suction hose to the suction line.

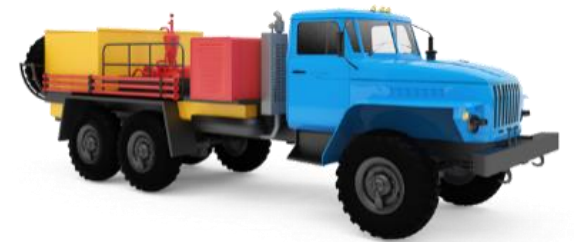

Fig. 1 Cementing truck (TSA-320)

Cement mixing unit $2 \mathrm{SMN}-20(2 \mathrm{CMH}-20)$ is designed for transportation of dry grouting materials, regulation of the supply of these materials by screw conveyors and preparation of grouting slurries for cementing oil and gas wells. The cement mixing unit consists of a hopper with two working screw conveyors and one loading screw conveyor with a folding bottom part, a power take-off box, 
a loading conveyor drive, a jet-type hydraulic mixing device with replaceable slotted nozzles and a control panel located at the rear of the unit.

Manifold unit BM-700 (БM-700, Russia) (Fig. 2) is designed for connection of pumping units to each other and to wellhead equipment during pumping of fluid in a well.

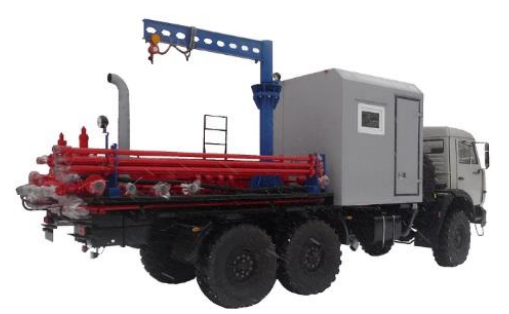

Fig. 2 Manifold unit

Standard piping scheme of cementing equipment is shown on Figure 3.

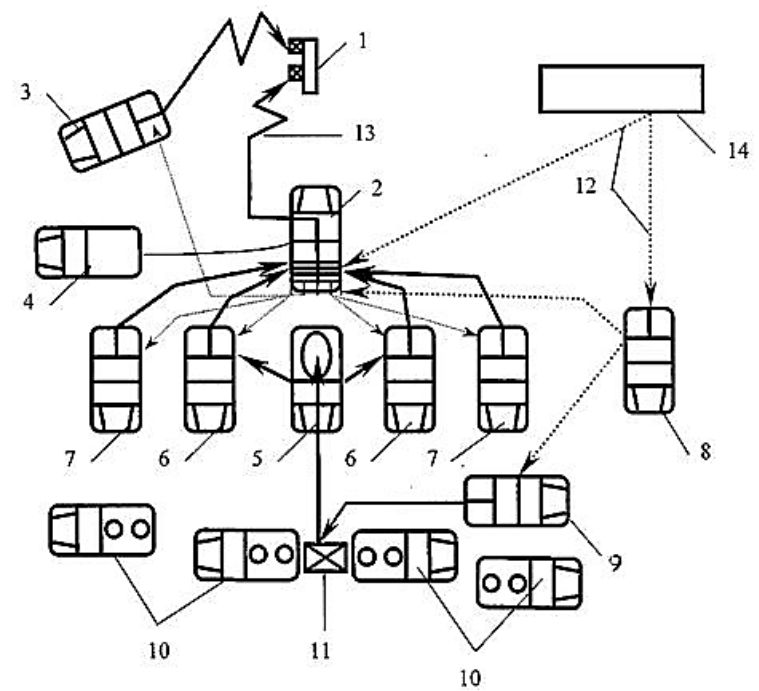

Fig. 3 Scheme of piping of cementing equipment:

1 - cement casing head; 2 - manifold unit (BM-700); 3 - cementing truck (TSA-320) involved in installation of a cement plug; 4 - control station SKUPTS-К (СКУПЦ-К); 5 - mud surge tank; 6 - cementing trucks (TSA-320) involved in injection of cement slurry and spacer fluid in a well; 7 - cementing trucks involved in injection of spacer fluid in a well; 8 - cementing truck (TSA-320) involved in injection of mixing fluid and spacer fluid in a well; 9 - cementing truck (TSA-320) involved in mixing of cement slurry; 10 - cement mixing unit (2SMN-20); 11 - mud hopper; 12 - mixing fluid and spacer fluid supply line; 13 - pressure line; 14 - containers for preparation of mixing liquid (spacer liquid)

In total, 13 units of equipment are involved in the cementing process. All of them must be tied and coordinated. According to the work procedure and safety requirements, 2 employees should work on each cementing unit, 1 employee on each cement mixing machine, 1 employee at the control station, 1 employee on the manifold unit. So, to carry out the operation we need 19 employees on equipment and also one manager, who will be responsible for the operation. Injection of cement slurry involves only two 2 TSA-320, while squeezing of slurry by a spacer liquid requires 4 TSA-320. The maximum injection rate of the 
cement slurry is 12 liters per second, and the maximum delivery rate of the spacer fluid is 24 liters per second.

In order to determine the time required for cementing and allowable pressures during this procedure, the cementing process was simulated in the software "BursoftProject" (Russia). The simulation results are presented in the diagrams in Figures 4-8.

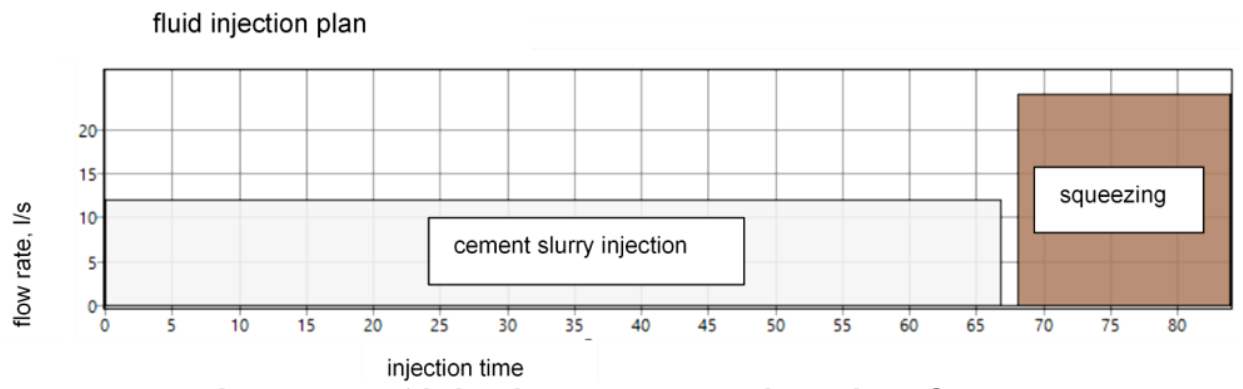

Fig. 4 Plan of injection and squeezing with TSA-320

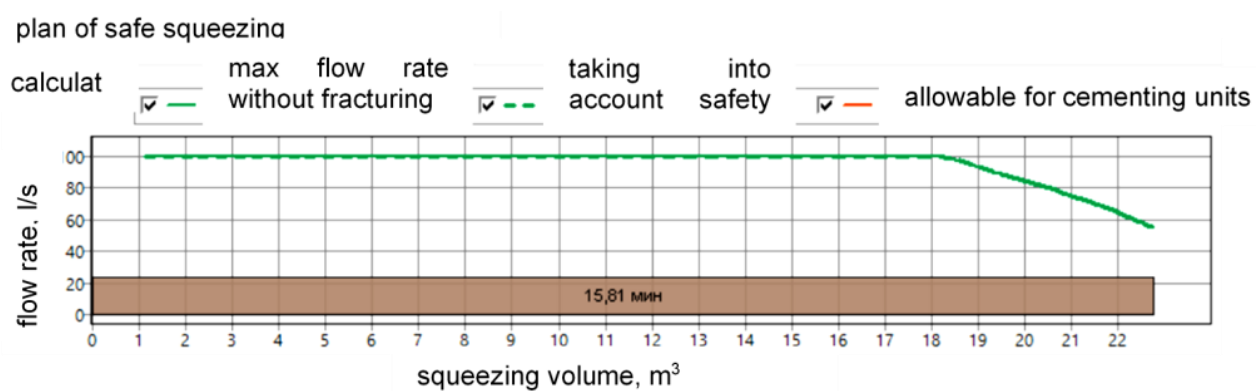

Fig. 5 Plan of safe squeezing with TSA-320

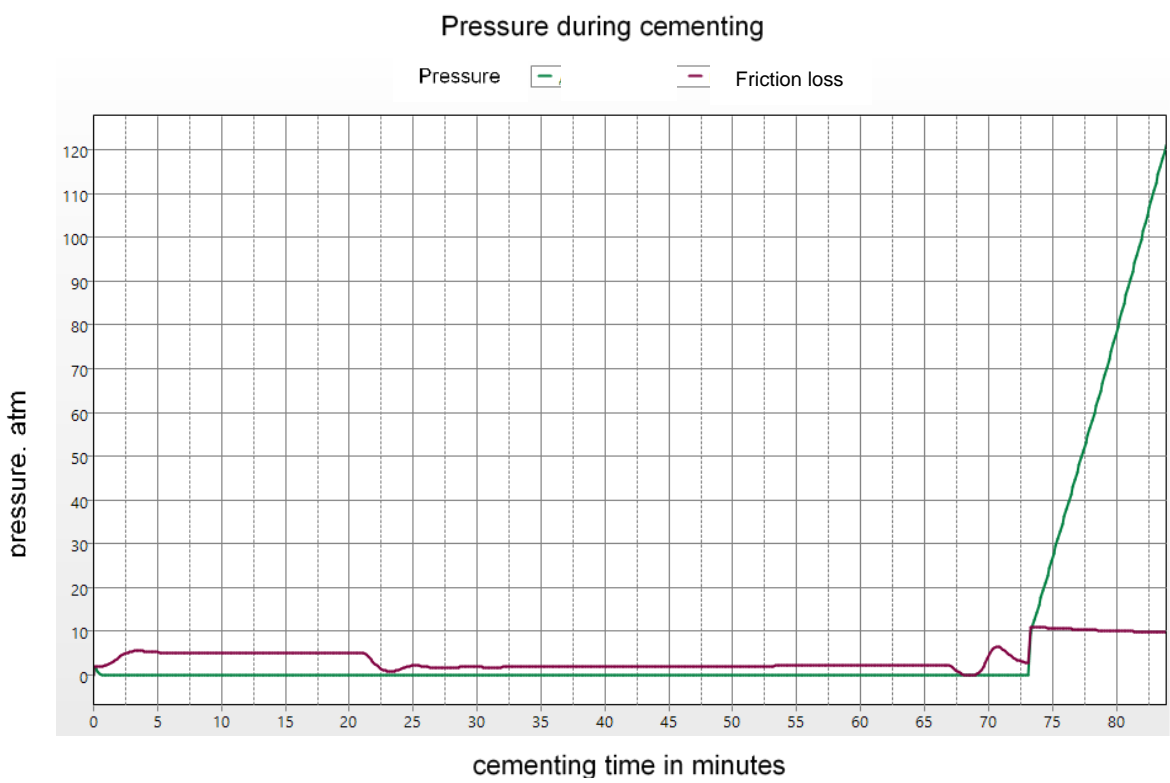

Fig. 6 Pressure on TSA-320 during cementing

Calculated total time for cementing operations is $83.9 \mathrm{~min}$, which is almost equal to maximum allowable time of 90 min $(0.75 \times 120$ min thickening time). 


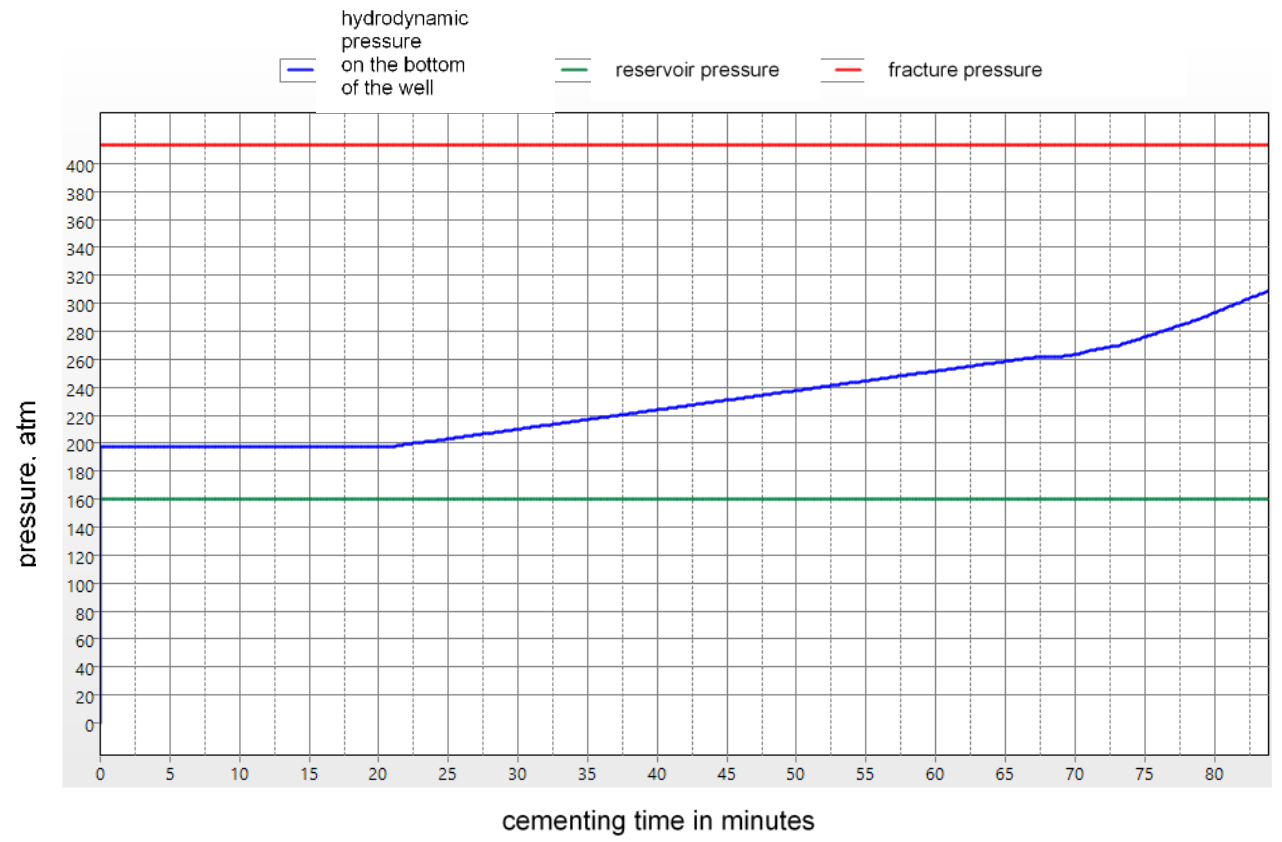

Fig. 7 Bottom-hole pressure in the process of cementing with TSA-320

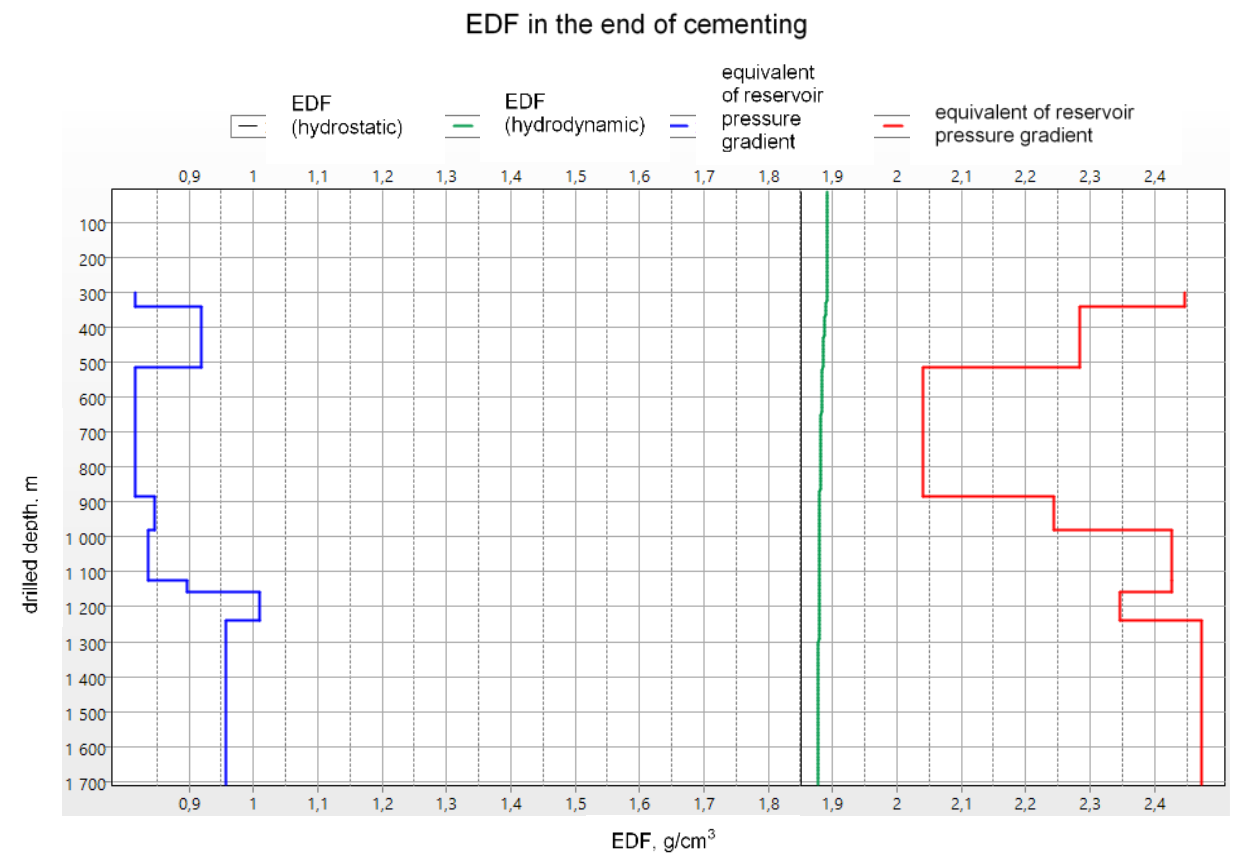

Fig. 8 Equivalent density of fluid (EDF) in motion and static compared with pressure gradients

The highest hydrodynamic pressure is created in a well during cement slurry squeezing. The hydrodynamic pressure does not exceed the limit when the spacer fluid is supplied with TSA-320 at a rate of 24 liters per second.

The maximum pressure is created on TSA-320 in the end of squeezing process and it reaches $121.19 \mathrm{~atm}$. It does not exceed the maximum allowable pressure on TSA-320 on the third gear which is $14 \mathrm{MPa}(138.2 \mathrm{~atm})$.

During all cementing process, hydrodynamic pressure on the bottom of the well does not exceed fracture pressure and always 10\% higher than reservoir 
pressure. Therefore, drilling under these conditions will not lead to oil and gas showings and fracturing of rocks near the shoe.

Since the fracture pressure gradients change nonlinearly with deepening of the well, it is necessary to simulate the hydrodynamic effect on the borehole walls throughout the wellbore. The greatest pressure is exerted on the borehole walls at the end of the cementing. The diagram (Fig. 8) shows the equivalent pressure at the end of cementing. The equivalent dynamic density of the cement slurry does not cause hydraulic fracturing in this horizon.

According to the results of modelling of cementing process, the next conclusions can be made:

1) The total time for cementing and squeezing is 83.9 minutes. This is close to the value of 90 minutes, which is the maximum permissible according to safety rules for the used cement slurry. Therefore, there are big technological risks of cementing, as slight violation of the cement slurry formulation can cause decrease in the thickening time or the sudden increase in time of the cementing operation by more than 6 minutes. The hydrodynamic pressures may increase until the pumping of the cement slurry stops and cement can stay inside the casing.

2) Pressure losses during cementing are 121.19 atm, maximum allowable pressure on TSA-320 is 138.2 atm. In case of an increase in viscosity, dynamic and static shear stresses also grow and pressure can exceed the value allowed for third gear. It will cause one of the units to stop, pressure will grow further leading to a forced shutdown of all the units. Then the squeezing process will be resumed on the second gear with a flowrate of 3.2 liters per second on each unit, which will result into exceeding of allowable cementing time.

3) Hydrodynamic pressure of cementing does not exceed fracture pressure of all layers.

\section{PROPOSED TECHNOLOGICAL SOLUTION}

To optimize the cementing technique the main ways to improve the process are increasing fluid supply capabilities, decreasing the amount of equipment units and reducing the number of maintenance staff. From the technological view, an increase in fluid supply capability provides the better displacement, creation of faster turbulent flow and decreases the time of cementing. A decrease in amount of equipment units and reduced maintenance personnel increase the safety of the process.

It is proposed to use a cementing complex of a new type, which includes: pumping facility UNBS2-600x70 (УНБC2-600x70, Russia); mobile cement bulk storage TsT-40-m02-01 (ЦТ-40-м02-01, Russia); cement carrier TsT-25-M-02 (ЦТ-25-M-02, Russia); cementing control station SKTsS-01 (СКЦС-01, Russia); TSA-320 (for water injection); water carriers (Dzhus et al., 2020; Andrusyak et al., 2017; Lao \& Zhou 2016; Li et al., 2019; Velychkovych et al., 2020; Grechnikov et al., 2018; Wang \& Liu 2017, Ivanova \& Zabinska, 2021). 
Pumping facility UNBS2-600x70 (Fig. 9) is designed for pumping of cement and nonaggressive operating fluids into oil \& gas wells in during cementing, jet perforation, sand washing, flushing and pressurizing operations during well stimulation and workover. The facility is equipped with recirculation system of continuous preparation and mixing of cement slurries. It consists of a mixing unit with pneumatic supply of dry cement and water and two tanks: mixing tank and surge tank, equipped with hydraulically driven agitators.

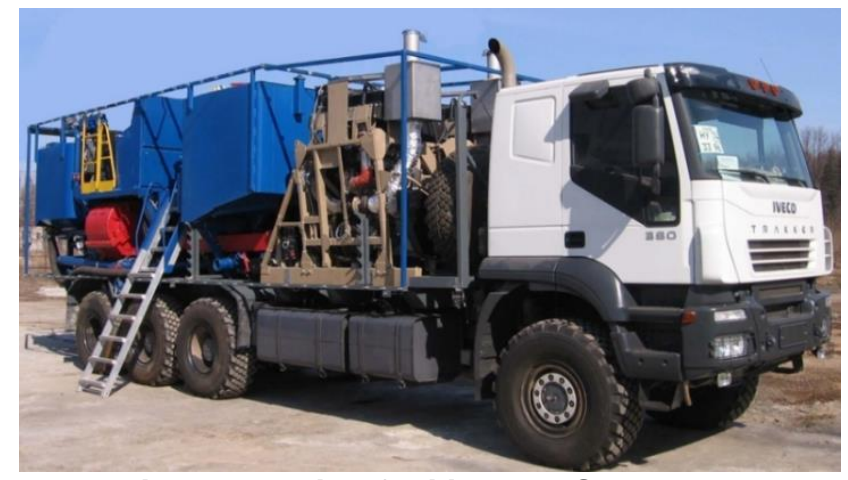

Fig. 9 Pumping facility UNBS2-600x70

The presence of two more powerful high-pressure pumps allows carrying out several operations simultaneously and decreases the probability of formation of plugs during injection of the slurry in a well. An enhancement of functions of such facility allows replacement of two pumping facilities and several mixing and surge tanks, which considerably decreases the expenses on cementing equipment and its maintenance. In addition, it allows decreasing labor input and energy consumption. What is more, the presence of heating system for drive and hydraulic parts of high-pressure pump, which is not included in common pumping units, allows using it in cold climate. The presence of the automatic system for preparation of cement slurry and density sensor in the recirculation system of the facility provides control of the density of prepared slurry without stopping the cement blending process. The rational assembly of the UNBS2-600x70 facility provides convenience for operators when servicing the unit.

Mobile cement bulk storages «TsT-40» (ЦТT-40, Russia) (Fig. 10) are designed for saving the quality of dry cement and supplying of cement flour into mixing unit. The unloading of the transported material is carried out using compressed air. The total geometrical capacity of the containers does not exceed $40 \mathrm{~m}^{3}$.

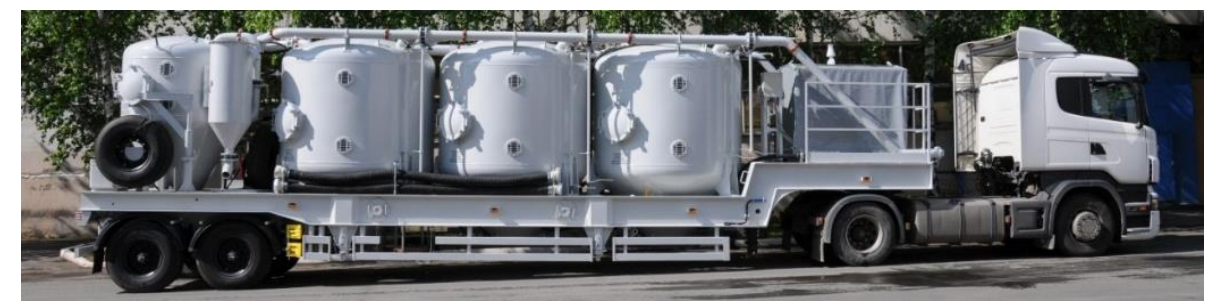

Fig. 10 Mobile cement bulk storage TsT-40 
Semitrailer cement carrier (Fig. 11) is designed for transportation of dry cement and other bulk materials with density up to $1.5 \mathrm{~g} / \mathrm{cm}^{3}$. The unloading of the transported material is carried out using compressed air. The geometric capacity of the tank does not exceed $25 \mathrm{~m}^{3}$. The mass of the transported cargo should not exceed 30 tons. The number of sections in the tank can vary from 1 to 4 .

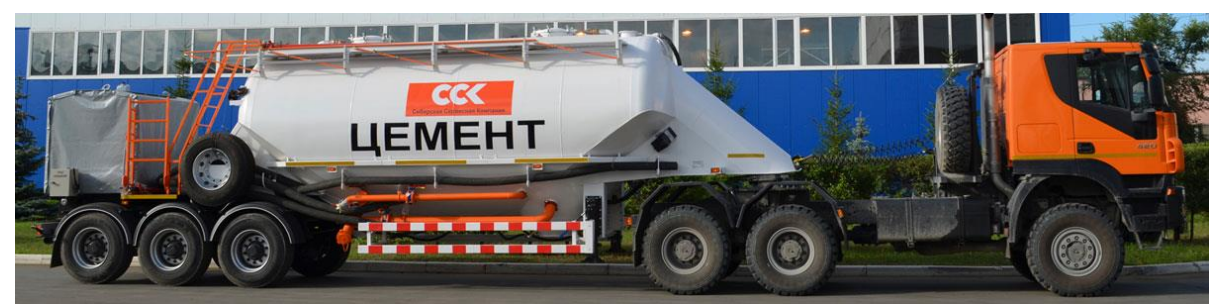

Fig. 11 Cement carrier TsT-25

Let us study the work of the station on the typical example of well cementing. We assume that single-stage cementing of annular space of surface pipe is required. Based on the parameters of well construction, the work plan is made; it includes description of steps and pumping volumes. Initial planned parameters are introduced into software of the station. The measuring tube of the station is mounted in the discharge line after the manifold unit right before the cementing head. Anything that enters the well passes through the measuring tube. The signals from the sensors of the monitored parameters are converted by the controller into a digital electrical signal, which is transmitted to the operator's workplace. Data can be transmitted either through the power cable through the power supply, or through the radio link (Fig. 12).

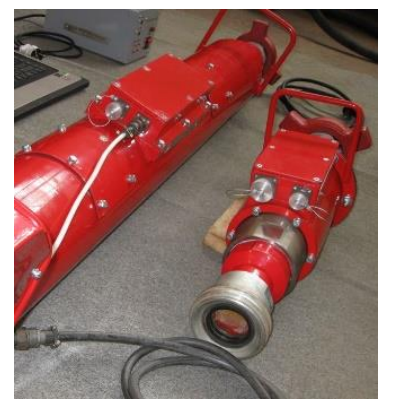

Fig. 12 Control station of technological operations SKTsS -01

According to the proposed scheme of well cementing, the following equipment is required: 1 dual pump cementing unit with mixing section, 1 mobile cement bulk storage, 2 cement carriers, 1 control station of cementing, 2 water carriers and 1 TSA-320 for water supply. To sum up, 8 units of equipment are required. The productivity of the new dual pump unit is 1 ton per minute for solution preparation, and up to 34 liters per second for injection into the well. The new cementing complex is used for injection; the UNBS2-600x70 facility is involved in the work. Environmental safety is among the main advantages of the new cementing complex. Technical fluid and drilling mud do not spill and, as a result, expenses for cementing of the production string are reduced. Typical complexes 
carry out work both on the territory of the Russian Federation and in the far and near abroad.

The layout of the proposed complex is shown in Fig. 13.

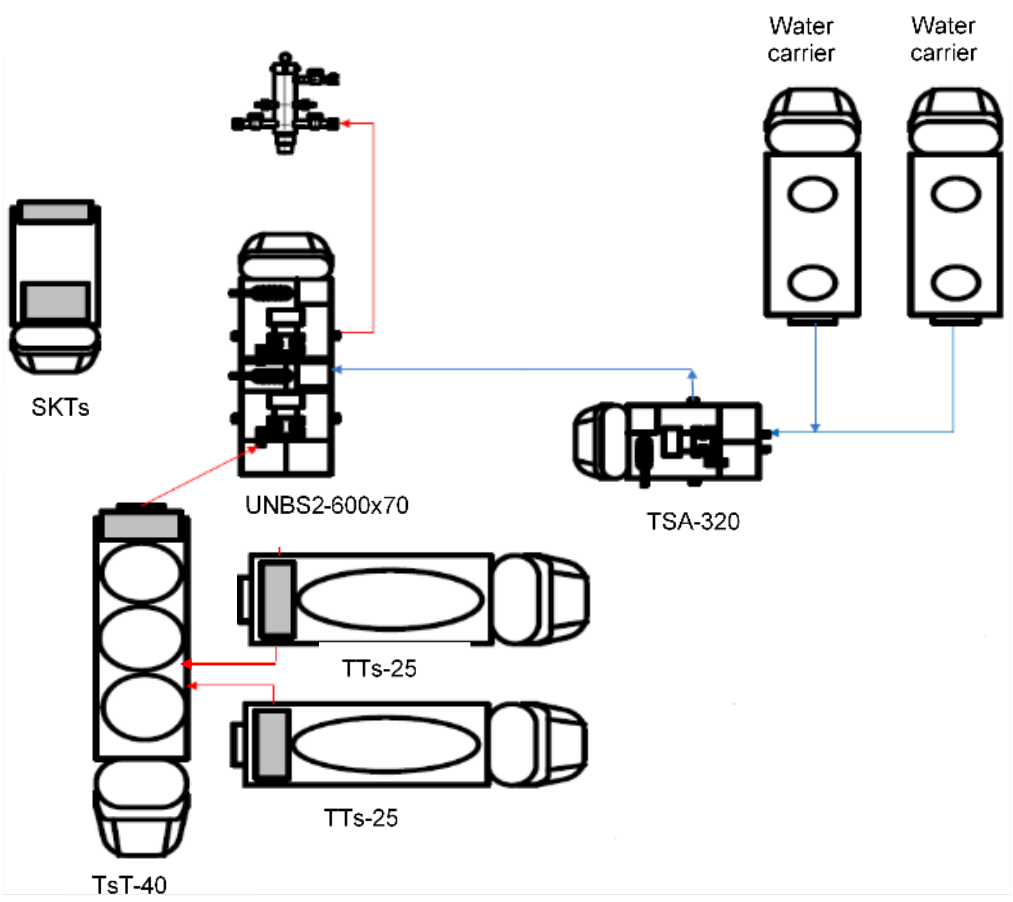

Fig. 13 Equipment layout during cementing operations involving UNBS2-600/70

In order to determine production parameters with the use of new cementing equipment, the cementing process was simulated in the software "BursoftProject". The simulation results are presented in the diagrams in Figures 14-18.

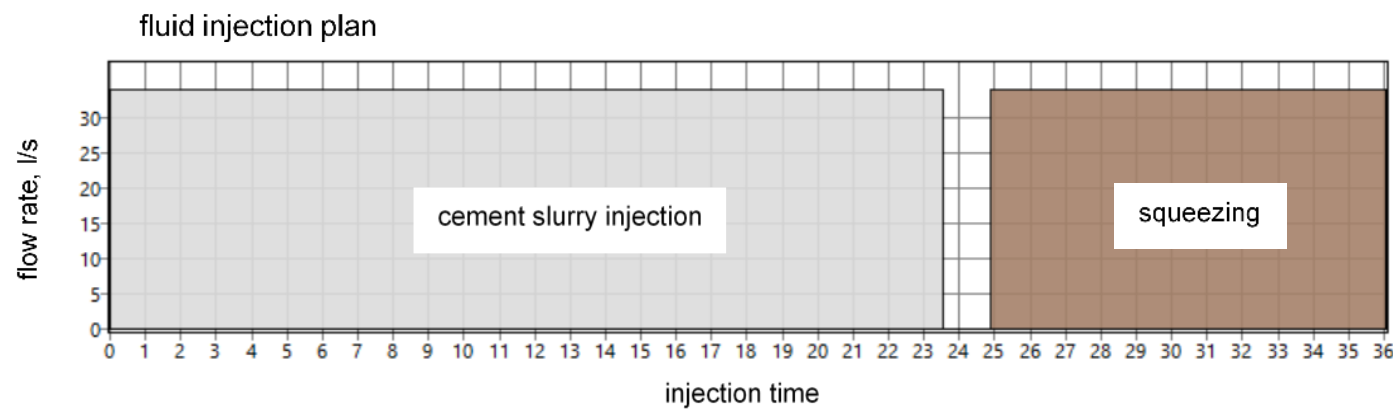

Fig. 14 Plan of injection and squeezing with UNBS2-600x70

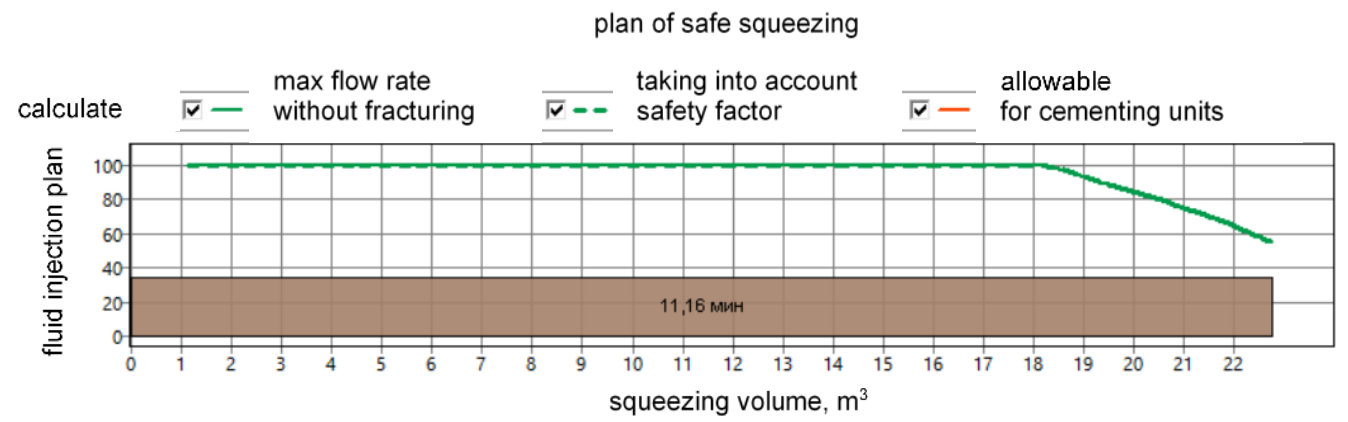

Fig. 15 Plan of safe squeezing 
Maximum output of UNBS2-600x70 high-pressure pumps is 34 liters per second. With this supply of cement slurry and spacer fluid the total time of cementing will be 36.05 min.

Hydrodynamic pressure does not exceed the limit under pumping rate of $34 \mathrm{l} / \mathrm{s}$. Maximum allowable flowrate is $\mathbf{5 5 . 1}$ liters per second.

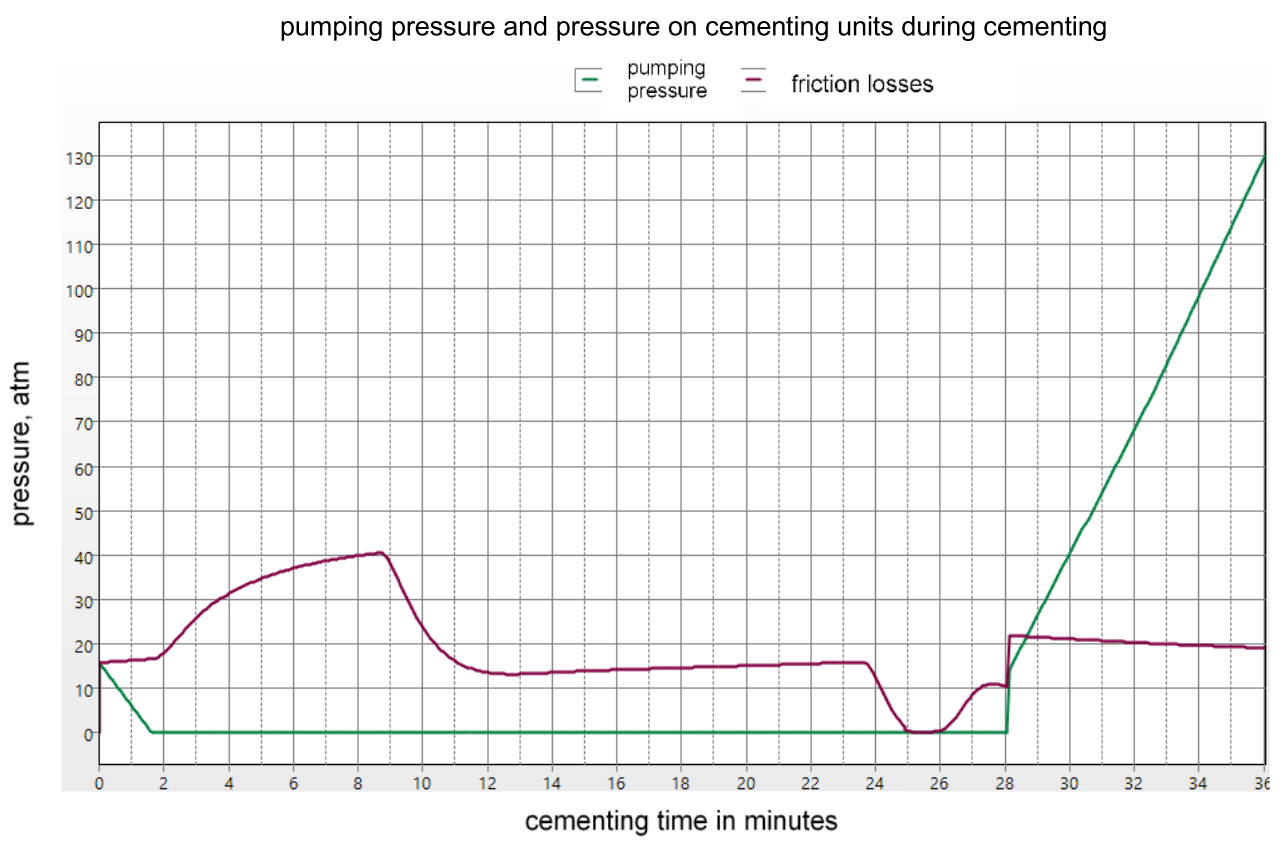

Fig. 16 Pressure on equipment during cementing

Maximum pressure is created on the UNBS2-600x70 pump in the end of squeezing and it reaches 129.6 atm. Maximum allowable pressure for UNBS2-600x70 is $50 \mathrm{MPa}$ (493.5 atm), and it is not exceeded during cementing.

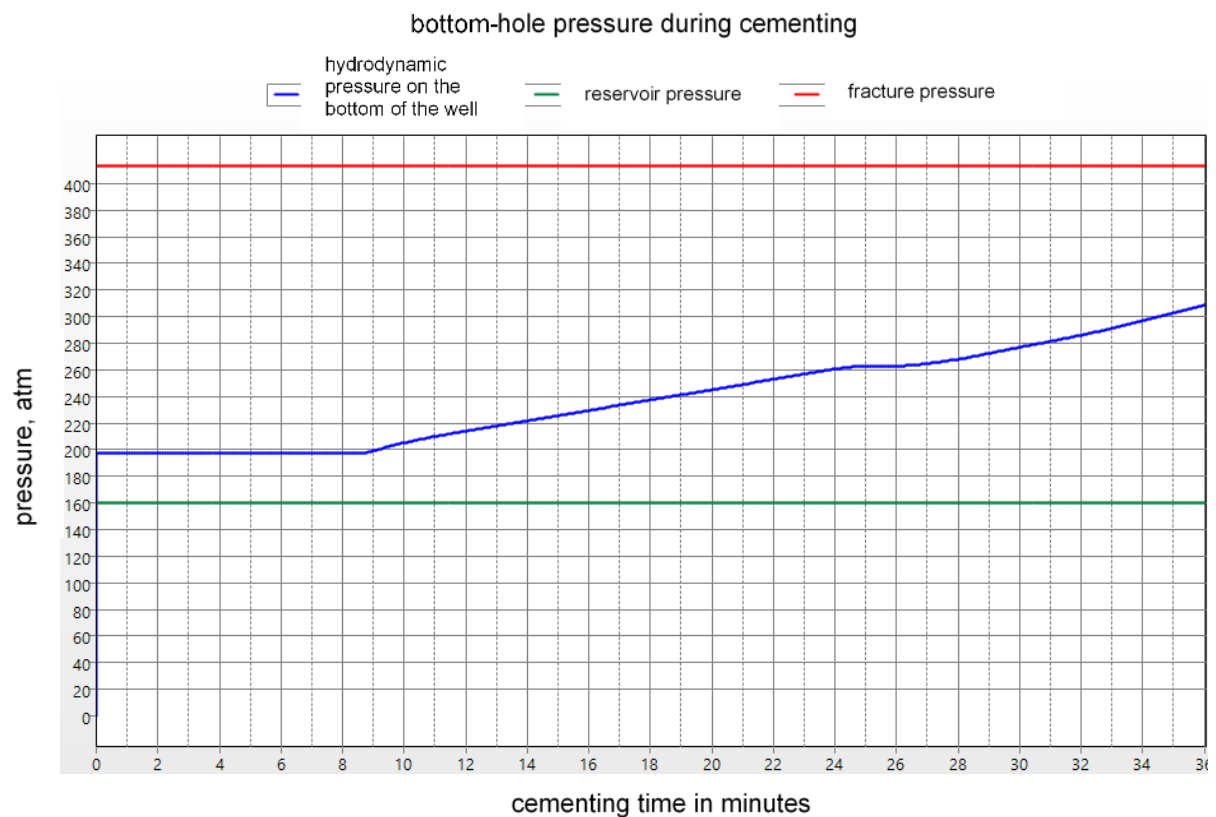

Fig. 17 Bottom-hole pressure in the process of cementing 
During all cementing process, hydrodynamic pressure on the bottom of the well does not exceed fracture pressure and always 10\% higher than reservoir pressure. Therefore, drilling under these conditions will not lead to oil and gas showings and fracturing of rocks near the casing shoe.

The greatest pressure on the borehole walls is reached at the end of the cementing. The diagram (Fig. 18) shows the equivalent pressure at the end of cementing. The equivalent dynamic density of the cement slurry does not cause hydraulic fracturing in the layer.

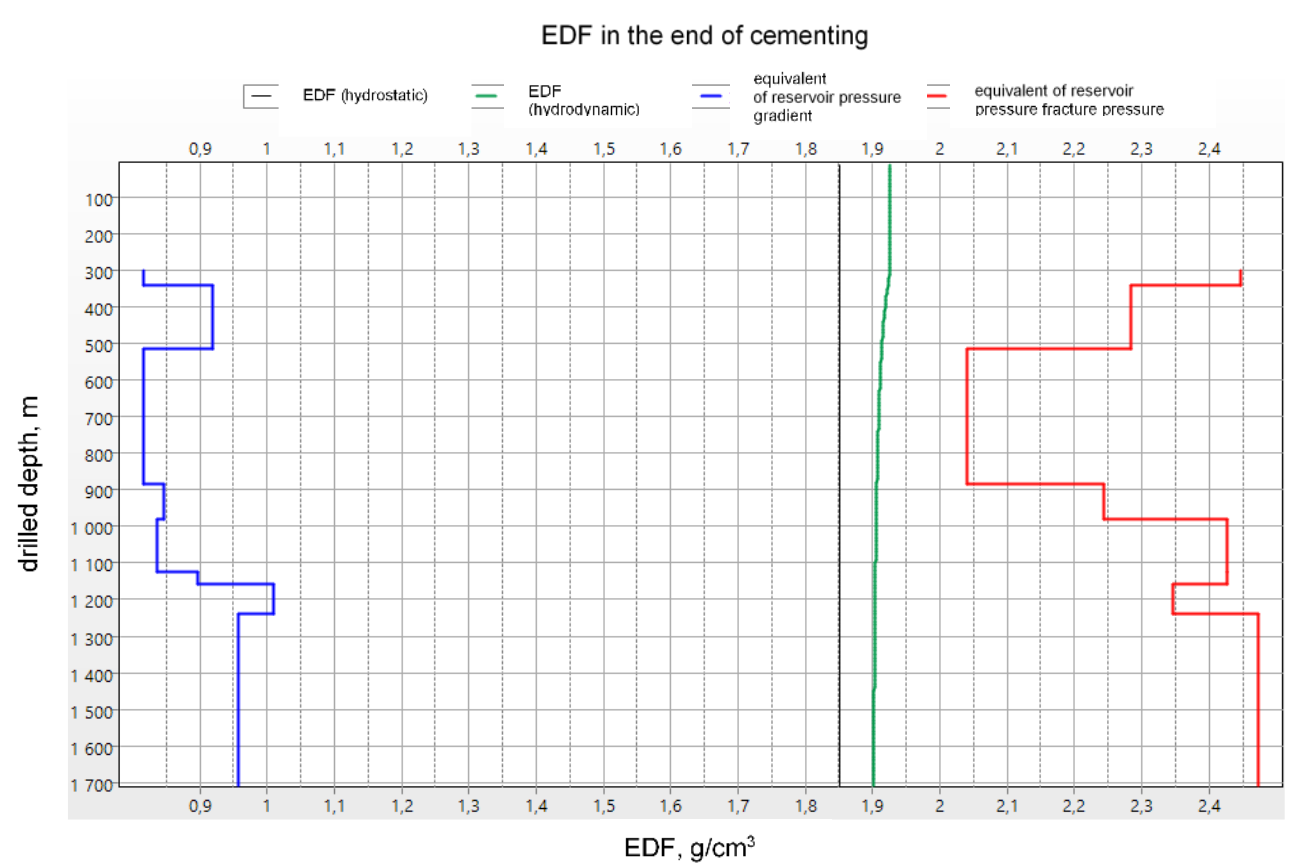

Fig. 18 Pressure gradients for layers and cementing hydrodynamics

According to the results of modelling of cementing process, the next conclusions can be made:

Total time of cementing operations is 36.05 minutes. Maximum permissible value according to safety rules for the used cement slurry is 90 minutes;

Maximum pressure during cementing using UNBS2-600x70 is $129.6 \mathrm{~atm}$ and it does not exceed the maximum allowable value of $493.5 \mathrm{~atm}$;

During cementing the pressure is distributed along the borehole, so it does not exceed the fracture pressure.

\section{Technological efficiency}

Proposed solution involving implementing of new cementing complex has the next technological effect:

- Decrease in cementing time from 83.9 to 36.05 minutes;

- Prevention from technological risks, connected with pressure limit in case of pumping with TSA-320 and cementing time;

- Increase in flow rate and speed of pumping of cement slurry, which improves the quality of cementing due to turbilization of the flow; 
- Decrease in the environmental damage, connected with spilling of technological fluids during cementing;

- Increase in safety of carried operations due to bigger spacing between equipment units and due to reduced amount of equipment units;

- Decrease in risk of human error due to reduced maintenance personnel and automatization of the process.

Proposed method of cementing with involves 8 equipment units, which require 10 employees.

Table 1 Services for cementing of production casing

\begin{tabular}{|c|c|c|c|c|c|c|}
\hline \multirow{2}{*}{$\begin{array}{l}\text { Service } \\
\text { description }\end{array}$} & \multirow{2}{*}{$\begin{array}{l}\text { Meas. } \\
\text { unit }\end{array}$} & \multirow{2}{*}{$\begin{array}{l}\text { Price, } \\
\text { rub. }\end{array}$} & \multicolumn{2}{|c|}{ Standard method } & \multicolumn{2}{|c|}{$\begin{array}{l}\text { Proposed complex } \\
\text { of equipment }\end{array}$} \\
\hline & & & $\begin{array}{c}\text { Cost } \\
\text { of } \\
\text { services, } \\
\text { rub } \\
\end{array}$ & Quantity & $\begin{array}{l}\text { Cost } \\
\text { of } \\
\text { services, } \\
\text { rub }\end{array}$ & Quantity \\
\hline $\begin{array}{l}\text { Work of TSA, } \\
\text { UNB } 160 \cdot 40\end{array}$ & hours & 2951.89 & 60218.56 & 20.4 & 1771.13 & 0.6 \\
\hline $\begin{array}{l}\text { Mileage of TSA, } \\
\text { UNB } 160 \cdot 40\end{array}$ & $\mathrm{~km}$ & 88.87 & 106644 & 1200 & 17774 & 200 \\
\hline $\begin{array}{l}\text { Preparation } \\
\text { of dry mixture }\end{array}$ & $\mathrm{t}$ & 611.17 & 79818.8 & 130.6 & 79818.8 & 130.6 \\
\hline $\begin{array}{l}\text { Work of mobile bulk } \\
\text { cement storage } \\
\text { TsT-40M-01 }\end{array}$ & hours & 2903.42 & & & 7548.89 & 2.6 \\
\hline $\begin{array}{l}\text { Mileage of mobile bulk } \\
\text { cement storage } \\
\text { TsT-40M-01 }\end{array}$ & $\mathrm{km}$ & 290.28 & & & 58056 & 200 \\
\hline $\begin{array}{l}\text { Work of TSA, } \\
\text { UNBS } 600 \cdot 70\end{array}$ & hours & 11420.58 & & & 29693.51 & 2.6 \\
\hline $\begin{array}{l}\text { Mileage of TSA, } \\
\text { UNBS } 600 \cdot 70\end{array}$ & $\mathrm{~km}$ & 275.22 & & & 55044 & 200 \\
\hline $\begin{array}{l}\text { Technological stand-by } \\
\text { of cement carrier } \\
\text { TsT-25M-02 }\end{array}$ & hours & 2233.96 & & & 5808.3 & 2.6 \\
\hline $\begin{array}{l}\text { Technological stand-by } \\
\text { of water carrier with } \\
\text { volume exceeding } \\
20 \mathrm{~m}^{3}\end{array}$ & hours & 1496.27 & & & 3890.3 & 2.6 \\
\hline $\begin{array}{l}\text { Mileage of water carrier } \\
\text { with volume exceeding } \\
20 \mathrm{~m}^{3}\end{array}$ & $\mathrm{~km}$ & 49.59 & & & 9918 & 200 \\
\hline $\begin{array}{l}\text { Work of cement carrier } \\
\text { with carriage up to } \\
8999 \mathrm{~kg}\end{array}$ & hours & 771 & 1542 & 2 & 1542 & 2 \\
\hline Cement carrier tag out & pcs & 49.63 & 198.52 & 4 & 198.52 & 4 \\
\hline Work of SKTs & hours & 1425.55 & 4846.87 & 3.4 & 3706.43 & 2.6 \\
\hline Mileage of SKTs & $\mathrm{km}$ & 47.51 & 9502 & 200 & 9502 & 200 \\
\hline Work of TsPSA & hours & 1570.67 & 31413.4 & 20 & & \\
\hline Mileage of TsPSA & $\mathrm{km}$ & 53.86 & 53860 & 1000 & & \\
\hline $\begin{array}{l}\text { Filling of TsPSA } \\
\text { on the base }\end{array}$ & $\mathrm{t}$ & 68.8 & 8985.28 & 130.6 & & \\
\hline Work of surge unit & hours & 1625.91 & 5528.09 & 3.4 & 4227.37 & 2.6 \\
\hline Mileage of surge unit & $\mathrm{km}$ & 54.02 & 10804 & 200 & 10804 & 200 \\
\hline TsPSA tag out & pcs & 86.91 & 434.55 & 5 & & \\
\hline $\begin{array}{l}\text { Planned accumulations } \\
(4 \%)\end{array}$ & & $4 \%$ & 15005.96 & & 11972.13 & \\
\hline In to & & & 388802.03 & & 311275.38 & \\
\hline
\end{tabular}


For the purpose of a comprehensive assessment of economic efficiency, it is necessary to calculate the cost of the operation according to the time standards and parameters of the projected well. The next parameters were accepted for calculation: the distance to the drilling site and back is $200 \mathrm{~km}$, preparation and filling of 130.6 tons of cement (according to calculation in section 2), equipment set-up time is 2 hours, cementing time for standard method is 1.4 hours (according to simulation in section 5), cementing time with new complex of equipment is 0.6 hours (according to simulation in section 5). The cost calculation shows the prices of OOO Tatburneft - LUTR. The calculation results are demonstrated in Table 1.

The payback of the equipment and the wages of the maintenance personnel are included in the cost of services. Consequently, the economic effect of one operation on the example of the given well is 77526.65 rubles.

\section{SUMMARY}

New cementing complex includes up-to-date pumping facility UNBS2-600x70 (УНБС2-600x70), mobile cement bulk storage TsT-40-m02-01 (ЦТ-40-м02-01), cement carrier TsT-25-M-02 (ЦТ-25-M-02), control station, water carriers and one TSA-320 for water supply. In comparison with standard scheme of cementing, the new complex provides increased supply of fluids, which has a positive effect on cementing quality and speeds up the process. Quality of cementing grows due to turbulization of the flow, which contributes to better filling of annular space by cement.

The most meaningful improvement is reducing of cementing time. The cementing process was modeled and it was found out that the cementing of the given well using standard method takes 83.9 minutes. This time for pumping of fluids is very close to the maximum allowed time for work -90 minutes $(75 \%$ of 120 minutes of thickening). In addition, the pressure at the end of the displacement is $121.2 \mathrm{~atm}$, which is close to the maximum allowable value for the TSA-320 in 3rd gear - $138.2 \mathrm{~atm}$. This increases the risks of the operation. Working with a new cementing complex allows reducing the pumping and squeezing time to $36.05 \mathrm{~min}$. This reduces technological risks and also opens up opportunities for improving the cement slurry formulation towards reducing the thickening time and, as a consequence, reducing the waiting-on-cement. The acceleration of the process by $47.85 \mathrm{~min}$ is one of the positive economic effects. To a greater extent, the economic effect consists of a decrease in the equipment and personnel involved in the work. The standard cementing scheme involves 13 units of equipment and 19 employees, and with the use of the new complex, 8 units of equipment and 10 employees are involved. Despite the fact that the equipment of the new complex is more expensive, the total cost of cementing will be lower. The total economic effect on the example of the projected well is 77.5 thnd rub. Technological and environmental efficiency confirms the feasibility of using the new complex. 


\section{ACKNOWLEDGEMENT}

This paper was financed from the resources of the Silesian University of Technology, project no. 13/010/BK_21/0057.

\section{REFERENCES}

Afanasyev V.A. (2012) "Optimization of well assemblies and well pump equipment of dual completion". Engineering Practice, no 2, pp. 36-38.

Andrusyak A., Grydzhuk J., Dzhus A., Steliga I. (2017) "Developing a method for the assessment of axial load in arbitrary cross-sections of the column of pumping rods", Eastern-European Journal of Enterprise Technologies, vol. 1, no. 7, pp. 3237. doi:10.15587/17294061.2017.92860

Baranov M.N., Božek P., Prajová V., Ivanova T.N., Novokshonov D.N., Korshunov A.I. (2017) "Constructing and calculating of multistage sucker rod string according to reduced stress". Acta Montanistica Slovaca, vol. 22, no. 2, pp. 107-115.

Dzhus A., Rachkevych R., Andrusyak A., Rachkevych I., Hryhoruk O., Kasatkin S. (2020) "Evaluation the stress-strain state of pumping equipment in the curvilinear sections of the wells". Management Systems in Production Engineering, Vol. 28, pp. 189-195 doi:10.2478/mspe-2020-0028

Grechnikov F.V., Rezchikov A.F., Zakharov O.V. (2018) Iterative Method of Adjusting the Radius of the Spherical Probe of Mobile Coordinate-Measuring Machines When Monitoring a Rotation Surface. Measurement Techniques. Vol. 61, pp. 347352.

Ivanova T.N., Żabińska I. (2021) "Modern Methods of Elimination of Lost Circulation in Directional Wells". Management Systems in Production Engineering". vol. 28, issue 1, pp. 65-74. doi:10.2478/mspe-2021-0009

L.-M. Lao, H. Zhou (2016) "Application and effect of buoyancy on sucker rod string dynamics", Journal of Petroleum Science and Engineering, vol. 146, pp. 264-271. doi:10.1016/j.petrol.2016.04.029

Li Q., Chen B., Huang Z., Tang H., Li G., He L. (2019) "Study on Equivalent Viscous Damping Coefficient of Sucker Rod Based on the Principle of Equal Friction Loss", Mathematical Problems in Engineering. doi:10.1155/2019/9272751

Moroz L., Uhrynovskyi A., Popovych V., Busko B., Kogut G. (2020) "Effectiveness research of physical and chemical methods appfication for oil recovery enhancing using the asp for the strutynsky oil field conditions". Management Systems in Production Engineering, Vol. 28, Issue 2, pp. 104-111. doi:10.2478/mspe-20200016

Savenok O.V., Povarova L.V., Kusov G.V. (2020) "Application of superdeep drilling technology for study of the earth crust". IOP Conference Series: Earth and Environmental Science. pp. 052-066.

Wang D.-Y., Liu H.-Z., (2017) "Dynamic modeling and analysis of sucker rod pumping system in a directional well", Lecture Notes in Electrical Engineering, vol. 408, pp. 1115-1127. doi:10.1007/978-981-10-2875-5_90

Velychkovych A., Petryk I., Ropyak L. (2020) "Analytical Study of Operational Properties of a Plate Shock Absorber of a Sucker-Rod String", Shock and Vibration. doi:10.1155/2020/3292713 
Abstract: Cementing of casing string is a final operation before the next stage of well construction; it provides maximum operational life of the well. Cementing of casing string is carried out with the use of technology, based on squeezing of the whole volume of drilling mud by special grouting composition. The main purposes of cementing include isolation of water-bearing horizon, strengthening of borehole walls in unconsolidated and unstable rocks. Well cementing process is divided into five subsequent operations. Firstly, grouting mixture is prepared in concrete mixers (cementing units) with necessary water-to-cement ratio and additives. Secondly, prepared grouting solution is injected in a well. Thirdly, the solution is squeezed into the space between the casing pipes and wellbore walls. Then it is necessary to wait until the cement sheath is hardened. And at last, quality control is carried out. For convenient transportation, the equipment for well cementing is installed on the truck chassis (KAMAZ, URAL and etc.). All components are poured in concrete mixer, then the water is added and everything is being mixed until formation of uniform mass, which is later pumped in a well. Oil and Gas Industry Safety Regulations say that "calculated endurance of casing string cementing should not exceed $75 \%$ of time of cement thickening, established by laboratory tests». Therefore, it is necessary to carry out all operations of injection of fluids into the well as soon as possible without any incompliances of the cementing technology. With cementing material used and its water-to-cement ratio of 0.5 , the average time of cement thickening is 120 minutes, according to laboratory tests. Therefore, a set of operations of injection of fluids should not exceed 90 minutes.

Keywords: cementing of casing string, isolation of water-bearing horizon, cement slurry injection, squeezing 